\title{
An In Vitro Model of Gastric Inflammation and Treatment with Cobalamin
}

\author{
T. R. Elliott and A. L. Guildford \\ Brighton Studies in Tissue-Mimicry and Aided Regeneration (BrightSTAR), Brighton Centre for Regenerative Medicine, \\ School of Pharmacy and Biomolecular Sciences, University of Brighton, Lewes Road, Brighton BN2 4GJ, UK \\ Correspondence should be addressed to A. L. Guildford; a.l.guildford@brighton.ac.uk
}

Received 10 January 2017; Revised 26 April 2017; Accepted 7 May 2017; Published 6 June 2017

Academic Editor: Han J. Moshage

Copyright (C) 2017 T. R. Elliott and A. L. Guildford. This is an open access article distributed under the Creative Commons Attribution License, which permits unrestricted use, distribution, and reproduction in any medium, provided the original work is properly cited.

\begin{abstract}
Pernicious anaemia (PA) is an autoimmune condition where antibodies target intrinsic factor and parietal cells, reducing the patient's ability to absorb cobalamin promoting atrophic gastritis. Treatment guidelines are based on excretion data of hydroxocobalamin from healthy individuals obtained 50 years ago. This manuscript describes the use of phorbol 12-myristate 13acetate (PMA) to stimulate low grade inflammation in an epithelial colorectal cell line to assess the efficacy of methylcobalamin and hydroxocobalamin. Nitric oxide increased significantly in cells exposed to higher doses of PMA $(100 \mathrm{ng} / \mathrm{ml}, 150 \mathrm{ng} / \mathrm{ml}$, and $200 \mathrm{ng} / \mathrm{ml}$ ) accompanied by a loss of the characteristic cobblestone morphology with no negative effect on cell activity or viability. A significant reduction in nitric oxide production was associated with the addition of $200 \mathrm{pg} / \mathrm{ml}$ hydroxocobalamin, alongside a return to the characteristic cobblestone morphology. This study highlights the use of PMA to promote low grade inflammation in human cell lines to model gastric inflammation associated with autoimmunity; furthermore it raises questions regarding the concentration of cobalamin administered clinically to restore cell functionality, feasibly allowing the patient to receive reduced quantity of the vitamin more regularly, providing the patient with levels which are akin to dietary intake.
\end{abstract}

\section{Introduction}

Patients with inflammatory bowel conditions often suffer from cobalamin deficiency [1]. It can also lead to pernicious anaemia (PA) an autoimmune condition associated with atrophic gastritis resulting in further gastric inflammation. In atrophic gastritis the parietal cells [2] are destroyed by autoantibodies towards the $\mathrm{H}^{+} \mathrm{K}^{+}$-ATPase on the surface of the cell [3]. This destruction leads to the decreased secretion of intrinsic factor (IF), a glycoprotein [4] essential for the absorption of cobalamin [5]. Oral B12 has been trialled; however only $8 \%$ of UK patients surveyed were on oral or sublingual medication [6]. Intramuscular injection is the most frequently administered form of treatment. Untreated cobalamin deficiency causes psychological symptoms such as depression, anxiety, and Alzheimer's disease. Subacute cerebral degeneration is a severe but frequently seen symptom which presents as general weakness, paraesthesia, abnormal gait, stiffness, and limb weakness [7].
Cobalamin is an essential water soluble vitamin [8] required as a coenzyme for methionine synthase and methylmalonyl-CoA mutase [4], in the methylation of DNA and the Krebs cycle, respectively. Cobalamin is an organometallic compound with a corrin ring structure surrounding a cobalt molecule [9]. It cannot be synthesized by the body and must be taken in through the diet. Cobalamin exists in four forms: hydroxocobalamin, methylcobalamin, cyanocobalamin, and adenosylcobalamin. Methylcobalamin and adenosylcobalamin are biologically active forms of cobalamin [10] whereas hydroxocobalamin and cyanocobalamin are inactive. In previous studies the active forms of cobalamin were found to be protective against cell death induced by increased homocysteine [11]. Elevated homocysteine levels have been previously linked with an increased risk of myocardial infarction and Alzheimer's disease. Methylcobalamin, acting as a coenzyme with methionine synthase, converts homocysteine to methionine. Therefore it is not surprising that $98 \%$ of 
patients with cobalamin deficiency have an increased total homocysteine level [12].

The recommended treatment for cobalamin deficiency is injections of cobalamin. In the UK patients receive subcutaneous injections of hydroxocobalamin every 12 weeks [6]; however $64 \%$ of participants of a survey by the PA Society (UK) were unhappy with their treatment [6] due to symptom recurrence before their next injection. It is essential that patients receive effective and appropriate treatment for the rest of their lives to ensure a good a quality of life. The current BNF treatment regime in the UK was based on a 1968 paper [7] which studied cobalamin excretion. They found the inactive hydroxocobalamin was retained for longer in the body than the active cyanocobalamin. However, the paper cohort was small, 13 in total, and none of the participants were diagnosed with PA, B12 deficiency, or associated transport problems. To our knowledge, no further research has been undertaken in subjects with PA or associated gastritis to understand the impact of the disease on cobalamin excretion or more importantly its direct cellular effect.

Nitric oxide (NO) has been implicated in gastric inflammation, along with NO synthase (NOS). These have been shown to contribute to the pathology of inflammation by causing cell cytotoxicity [13]. Cobalamin has been shown to reduce the bioactivity of $\mathrm{NO}$, as $\mathrm{NO}$ will bind to the corrin ring structure of cobalamin [14]. A 2009 study found that hydroxocobalamin was the most effective form of cobalamin in inhibiting NOS [14].

Caco- 2 cells are a human colon adenocarcinoma cell line that has been used to model the gastric epithelium for almost 30 years [15]. In vitro models using Caco- 2 cells to mimic gastric inflammation [16] in coeliac disease found that a combination of phorbol myristate acetate (PMA) and IFN- $\gamma$ was the best inducer of $\mathrm{NO}$ production and therefore inflammation. Another study found that PMA alone was sufficient to induce inflammation in Caco-2 cells though at a lower level compared to IFN- $\gamma$ [15]. In this experimental model inflammation will be induced using PMA alone to mimic a low level of acute gastric inflammation.

The aim of this study is to develop an in vitro model capable of mimicking low grade gastric inflammation and to use this model to investigate the activity of clinically relevant levels of cobalamin as defined by earlier studies and finally to enhance our current understanding between the impact of active and inactive cobalamin in the developed gastric model of inflammation.

\section{Materials and Methods}

2.1. Gastric Inflammation Study. Caco-2 cells were subcultured at a subcultivation ratio of $1: 5$ in DMEM 10\% FBS $\left(37^{\circ} \mathrm{C}, 95 \% \mathrm{O}_{2}, 5 \% \mathrm{CO}_{2}\right) ; 1 \times 10^{5}$ cells were seeded in to 24 -well plates and allowed to adhere for 24 hours. Cells were spiked with phorbol 12-myristate 13 -acetate (PMA) $(0,50,100,150$, and $200 \mathrm{ng} / \mathrm{ml}$ ) and incubated for 24 and 48 hours. After incubation media were removed and centrifuged, processed for the Griess assay and MTT assays, respectively.
TABLE 1: Cobalamin concentration and the clinical relevance.

\begin{tabular}{lc}
\hline Cobalamin concentration $(\mathrm{pg} / \mathrm{ml})$ & Clinical relevance of value \\
\hline 0 & Control value \\
200 & UK minimum of normal \\
& range [21] \\
500 & Asian minimum of normal \\
range [22] \\
750 & Midrange of reference \\
& range \\
1000 & UK maximum of normal \\
& range [21] \\
5000 & Five times greater than \\
& maximum range to test for \\
& toxicity of extremes \\
\hline
\end{tabular}

2.1.1. NO Production. Griess assay (Promega, UK): sulfanilamide solution was added to $50 \mu \mathrm{l}$ of each sample and incubated in the dark prior to the addition of $\mathrm{N}$ (1-naphthyl)ethylenediamine dihydrochloride (NED). After incubation the absorbance was read at $520 \mathrm{~nm}$. The limit of detection is $2.5 \mu \mathrm{M}(125 \mathrm{pmol})$ nitrite.

2.1.2. Cell Activity. MTT (Sigma-Aldrich, UK) was added to the remaining wells and incubated; formazan crystal in wells was dissolved using MTT solubilization solution and the absorbance measured at $570 \mathrm{~nm}$.

2.1.3. Cell Viability and Morphology. 5-Chloromethylfluorescein diacetate in DMSO $(10 \mu \mathrm{M})$ (Sigma) was added to wells and incubated with media (DMEM + 10\% FBS) prior to fixing in formalin $(3.7 \%)$ and observing under the confocal microscope (Leica, UK).

2.2. Active Cobalamin Toxicity Study. Caco-2 cells were seeded at $1 \times 10^{5}$ and allowed to adhere for 24 hours. Cells were spiked with methylcobalamin at clinically relevant concentrations (Table 1) and incubated for 24 hours. Supernatant and cells were processed as above for NO production (Section 2.1.1) and cell viability using MTT (Section 2.1.2).

2.3. In Vitro Model Study. Caco-2 cells were seeded $\left(1 \times 10^{5}\right)$ to 24 -well plates and allowed to adhere for 24 hours in DMEM $10 \% \mathrm{FBS}\left(37^{\circ} \mathrm{C}, 95 \% \mathrm{O}_{2}\right.$, and $\left.5 \% \mathrm{CO}_{2}\right)$. Cells were spiked with $150 \mathrm{ng} / \mathrm{ml}$ phorbol-12-myristate 13-acetate and methylcobalamin $(0,200,500,750$, and $1000 \mathrm{pg} / \mathrm{ml})$ or hydroxocobalamin $(0,200,500,750$, and $1000 \mathrm{pg} / \mathrm{ml})$ and incubated for 24 hours at $37^{\circ} \mathrm{C}, 5 \% \mathrm{CO}_{2}$. Supernatants and cells were processed for NO production using the Griess assay (Section 2.1.1) and cell viability via MTT assay (Section 2.1.2). Cell morphology was observed using phalloidin and rhodamine staining; the cells were fixed in $3.7 \%$ formalin prior to washing in sterile PBS and incubation in phalloidin rhodamine; after incubation the dye was removed and the samples were viewed under the confocal microscope.

2.4. Statistics. All statistical information was determined using one-way ANOVA and Tukey's method and 95\% confidence intervals using Minitab Statistical software. 


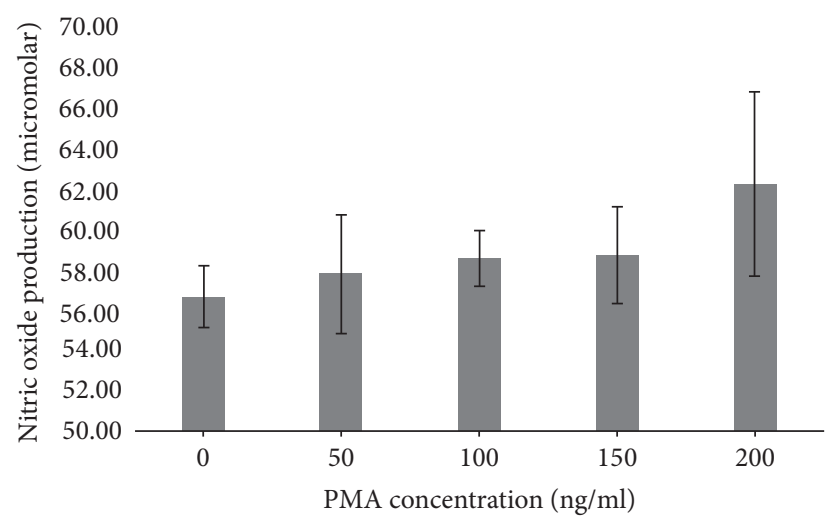

FIGURE 1: Nitric oxide production from colorectal adenocarcinoma (Caco-2) cells after 24-hour culture with phorbol 12-myristate 13acetate (PMA).

\section{Results}

\subsection{Gastric Inflammation Study}

3.1.1. Nitric Oxide Production. Caco-2 cells incubated with PMA showed a positive significant increase in cell production of nitric oxide with 100,150 , and $200 \mathrm{ng} / \mathrm{ml}$ compared to cells incubated with 0 and $50 \mathrm{ng} / \mathrm{ml} \mathrm{PMA} \mathrm{(} p=0.0038)$ (Figure 1$)$.

3.1.2. Cell Activity. Cells incubated with PMA for 24 and 48 hours showed an increase in cell activity. Cells incubated for 24 hours demonstrated a significant increase in cell activity from $100 \mathrm{ng} / \mathrm{ml}$ reaching a peak at 150 and $200 \mathrm{ng} / \mathrm{ml}$, where the absorbance for cell activity was significantly greater than at 0,50 , and $100 \mathrm{ng} / \mathrm{ml}(p=0.0013)$. Cells at 48 hours demonstrated the greatest activity; indeed there was a significant increase in cell activity of all cells incubated for 48 hours $(p=0.7840)$; however the activity had plateaued and increasing the concentration of PMA did not influence cell activity (Figure 2).

3.1.3. Cell Viability and Morphology. Morphological changes were observed between the control cells incubated without PMA and those incubated with $150 \mathrm{ng} / \mathrm{ml}$ of PMA and above over 24 hours. Control Caco- 2 cells demonstrated a typical cobblestone morphology (Figure 3(a)), where the cells were of a similar size with an ovular shaped nucleus. In contrast, cells with $150 \mathrm{ng} / \mathrm{ml}$ PMA displayed an altered morphological appearance; the cells are clustered but have lost the stereotypical cobblestone morphology and regular nucleus, and rather the cells show a more atypical nucleus (Figure 3(b) white arrows) with identifiable filopodia and extrusions (data not shown).

\subsection{Active Cobalamin Toxicity Study}

3.2.1. NO Production. Cells incubated methylcobalamin demonstrated no significant changes in NO release compared to controls, and levels of the active cobalamin which reached a fivefold excess of clinical standards showed no significant

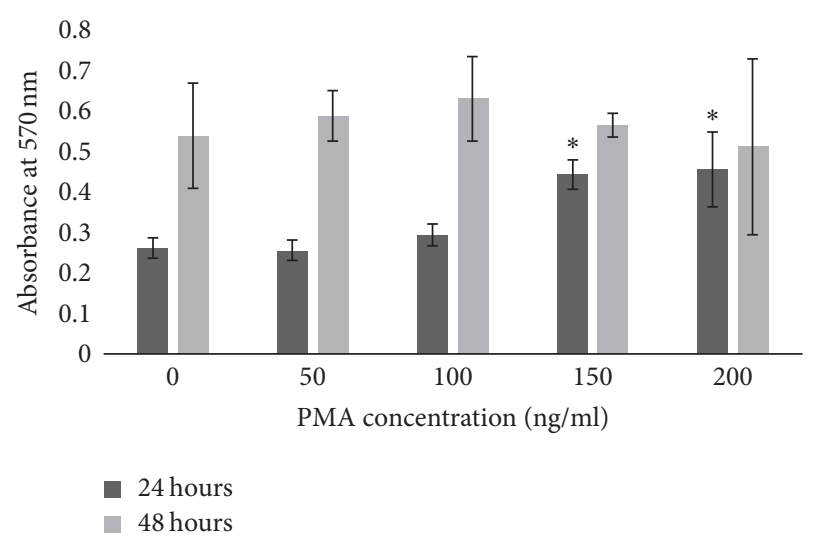

FIGURE 2: Cell metabolic activity as measured by MTT assay after 24hour and 48-hour incubation in culture with phorbol 12-myristate 13-acetate (PMA) ( ${ }^{*}$ significantly increased $\left.(p=0.0013)\right)$.

difference in the level of NO production $(p=0.1472)$ (Figure 4(a)).

3.2.2. Cell Activity. There was no significant statistical difference in Caco-2 cell activity after 24-hour incubation with different concentrations of methylcobalamin $(p=0.3118)$ (Figure 4(b)) $(p=0.3118)$.

\subsection{In Vitro Model Study}

3.3.1. Methylcobalamin. There is a significant increase in cell activity with $750 \mathrm{pg} / \mathrm{ml}$ of methylcobalamin with PMA compared to all other concentrations of methylcobalamin $(p=0.0061)$ (Figure 5(a)). There is no significant statistical difference in NO production between cells with and without PMA at the same concentrations of methylcobalamin (Figure $5(\mathrm{~b}))(p=0.1839)$. The morphology of the cell (Figure 6) shows distinct changes from cells incubated with the addition of methylcobalamin. When incubated with the lowest clinical value of methylcobalamin $200 \mathrm{pg} / \mathrm{ml}$ (Figure 6(c)) the cells are elongated rather than cobblestone; they have a reduced cytoplasm and a rougher cell surface and they appear to have lost their ability to form a monolayer in comparison to the control Caco-2 cells (Figure 6(a)). Indeed, their overall appearance looks similar to that of the cells in the PMA control (Figure 6(b)) where the rougher cell surface is also associated with a change of the shape of the nucleus and a tendency towards more spiked cell morphology. The cells incubated with the highest dose of methylcobalamin $1000 \mathrm{pg} / \mathrm{ml}$ showed a mixed cell population where those on the tissue culture plastic demonstrated a flatter more rounded morphology, with a large round nucleus and a cytoplasm ratio akin to that of the cell control (Figure 6(a)) but these unlike the cell control were covered with a number of cells more representative of the PMA control with a more irregular nucleus and a reduction in cytoplasm (Figure 6(b)).

3.3.2. Hydroxocobalamin. No significant difference was observed in cell activity with PMA $(p=0.1941)$ (Figure 7(a)). However, NO production was significantly reduced with 


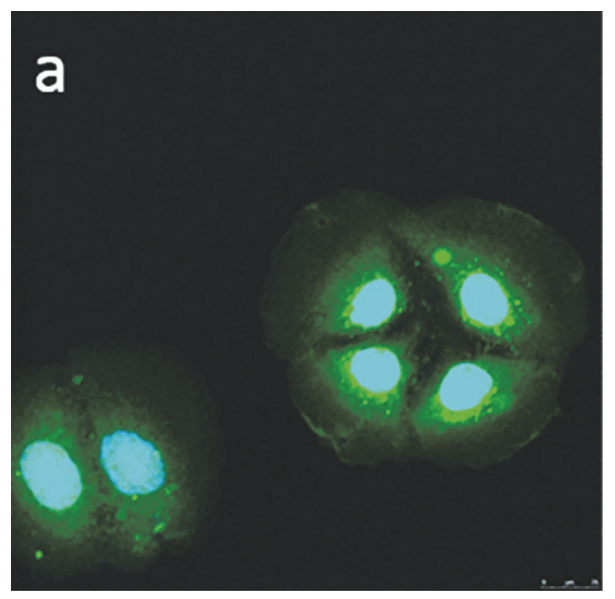

(a)

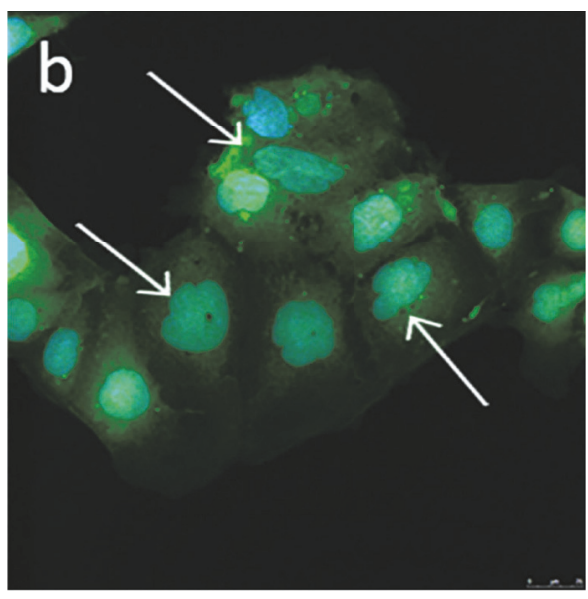

(b)

FIGURE 3: Colorectal adenocarcinoma (Caco-2) cells after 24-hour incubation with (a) cell culture medium and (b) cell culture medium spiked with $150 \mathrm{ng} / \mathrm{ml}$ phorbol 12-myristate 13-acetate (PMA). White arrows highlight nuclear changes.

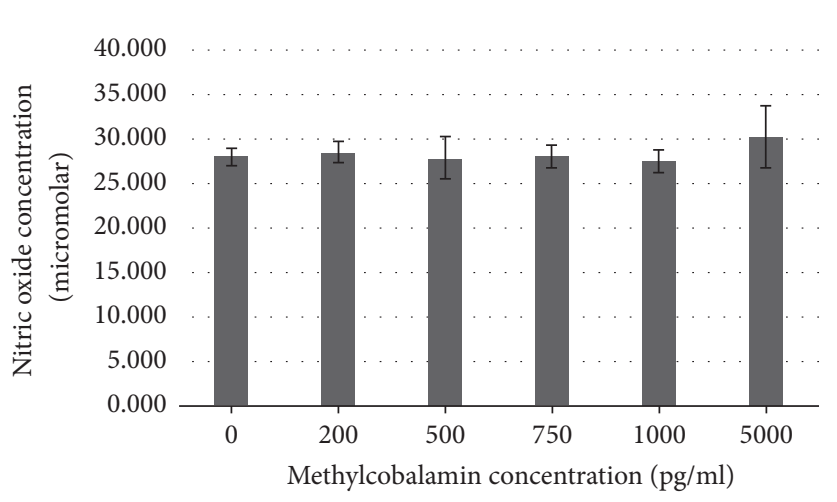

(a)

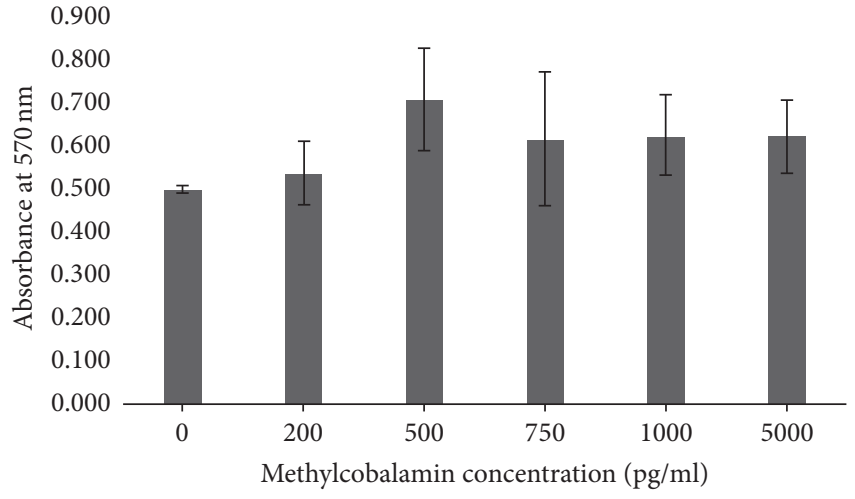

(b)

Figure 4: Colorectal adenocarcinoma (Caco-2) cells after 24-hour culture with methylcobalamin (0, 200, 500, 750, 1000, and 5000 pg.ml). (a) Nitric oxide production; (b) cell activity as measured by MTT.

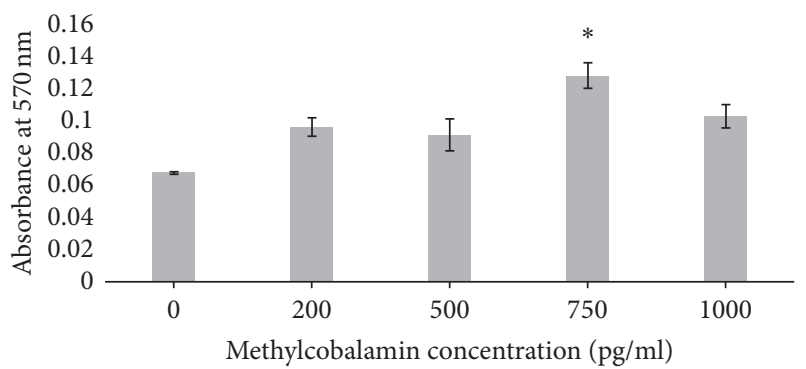

(a)

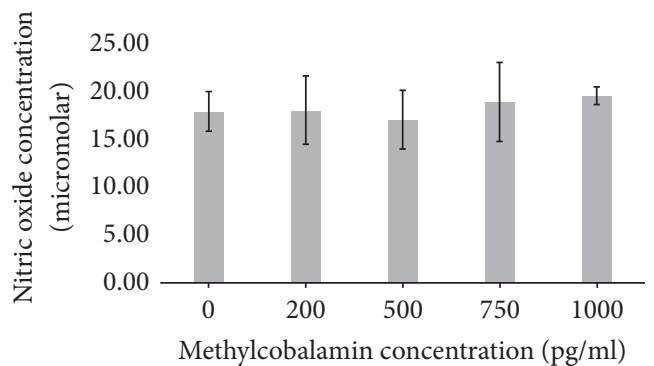

(b)

FIGURE 5: Colorectal adenocarcinoma (Caco-2) cells after 24-hour culture with $150 \mathrm{ng} / \mathrm{ml}$ phorbol 12-myristate 13 -acetate (PMA) and methylcobalamin $(0,200,500,750$, and $1000 \mathrm{pg} / \mathrm{ml})$. (a) Cell activity as measured by MTT; (b) nitric oxide production $\left({ }^{*}\right.$ significantly increased $p=0.0061$ ). 


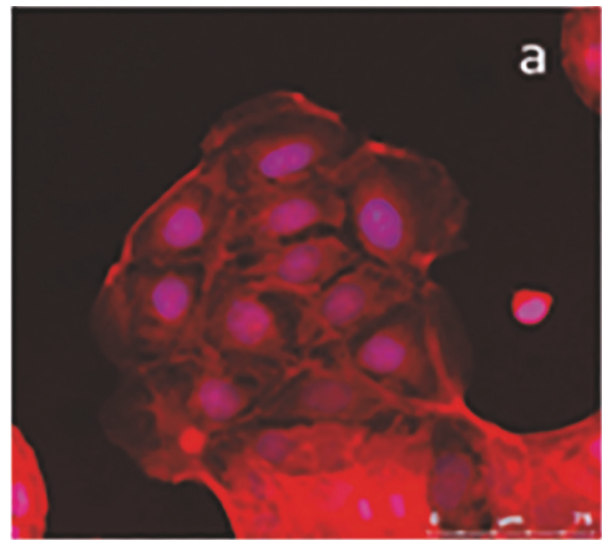

(a)

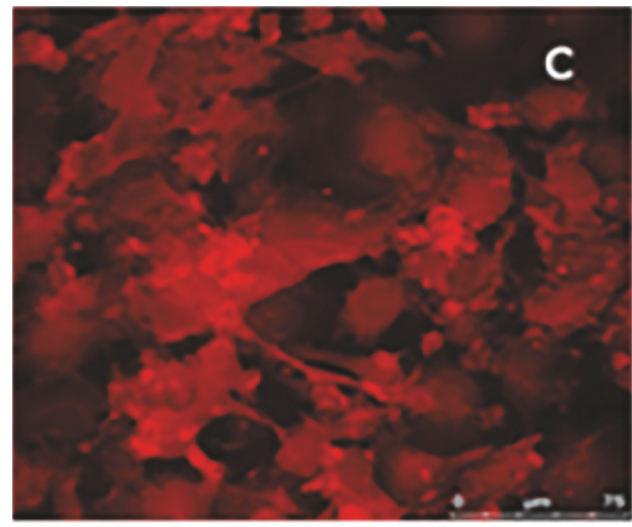

(c)

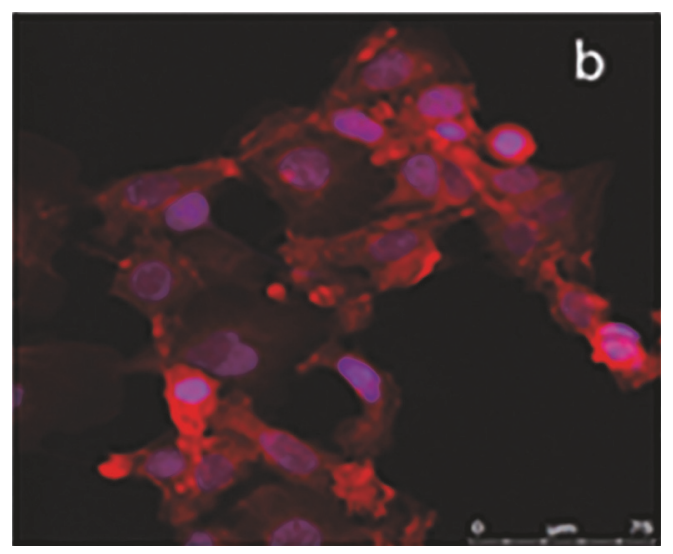

(b)

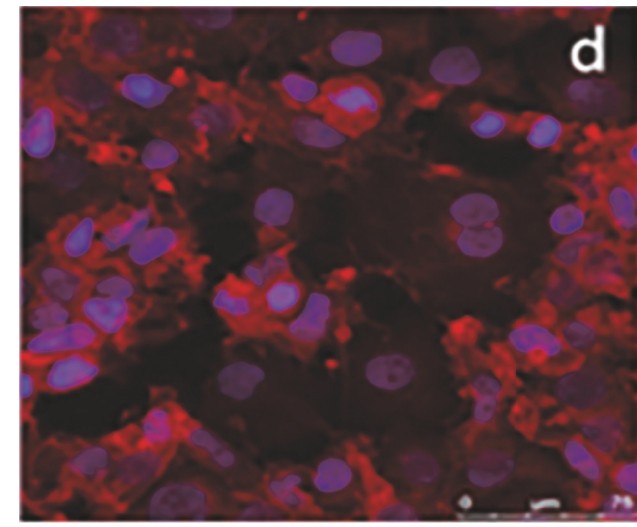

(d)

FIGURE 6: Colorectal adenocarcinoma (Caco-2) cells after 24-hour culture with (a) $150 \mathrm{ng} / \mathrm{ml}$ phorbol 12-myristate 13-acetate (PMA) (b) and $200 \mathrm{pg} / \mathrm{ml}$ methylcobalamin (c) or $1000 \mathrm{pg} / \mathrm{ml}$ methylcobalamin (d).

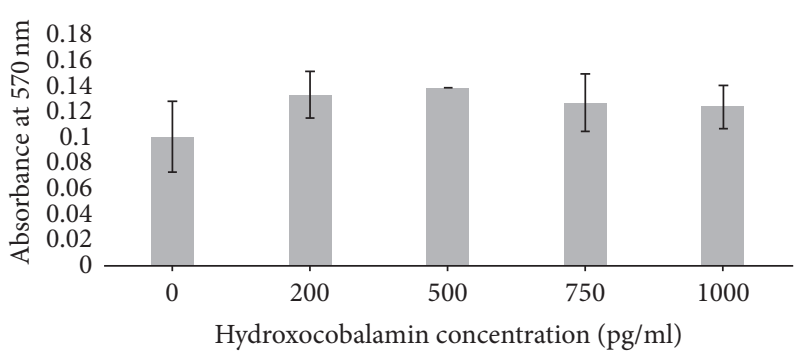

(a)

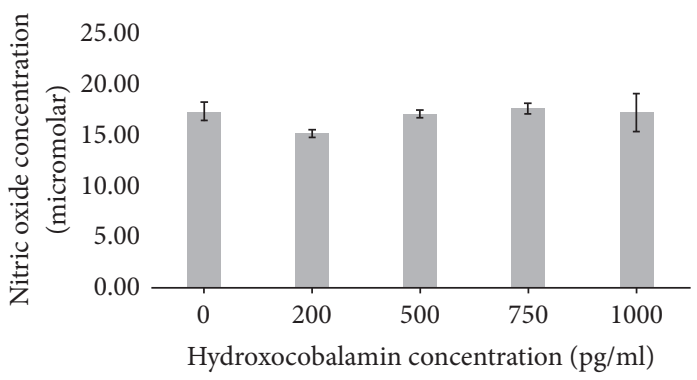

(b)

Figure 7: Colorectal adenocarcinoma (Caco-2) cells after 24-hour culture with $150 \mathrm{ng} / \mathrm{ml}$ phorbol 12-myristate 13-acetate (PMA) and hydroxocobalamin (0, 200,500, 750, and $1000 \mathrm{pg} / \mathrm{ml})$ : (a) cell activity as measured by MTT; (b) nitric oxide production.

the addition of $200 \mathrm{pg} / \mathrm{ml}$ hydroxocobalamin (Figure $7(\mathrm{~b})$ ) $(p=0.0008)$. Imaging of cell morphology highlighted a clear morphological change in Caco-2 cells incubated with PMA and hydroxocobalamin (Figure 8). As described cells incubated with PMA demonstrate an irregular nucleus and a lack of typical cobblestone morphology (Figure 8(b)), displaying filopodia extensions. Cells incubated with $150 \mathrm{ng} / \mathrm{ml}$ hydroxocobalamin start to demonstrate features of both populations with cells demonstrating regular nuclei and fewer projections (Figure 8(c)). Cells further resemble the controls cells when exposed to $1000 \mathrm{pg} / \mathrm{ml}$ hydroxocobalamin (Figure $8(\mathrm{~d})$ ), the cell shape and size having become regular; however the cells have not yet formed clear clusters seen in control cells (Figure 8(a)).

\section{Discussion}

For this study, PMA was used as the inducer of inflammation as described by Chen and Kitts [15]. PMA activates protein kinase $\mathrm{C}$ (PKC) in epithelial cells [17] by mimicking 


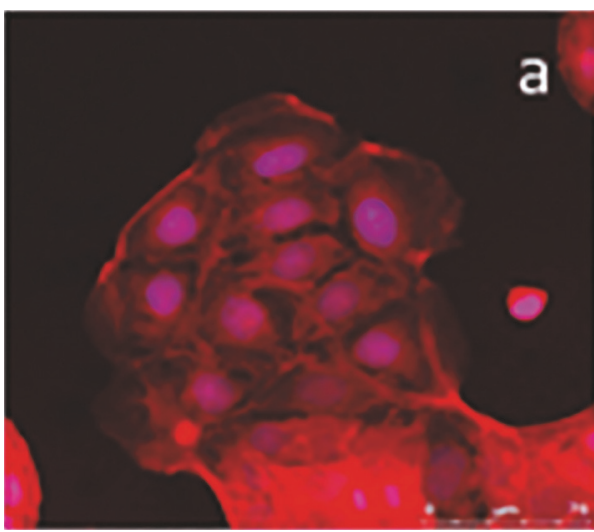

(a)

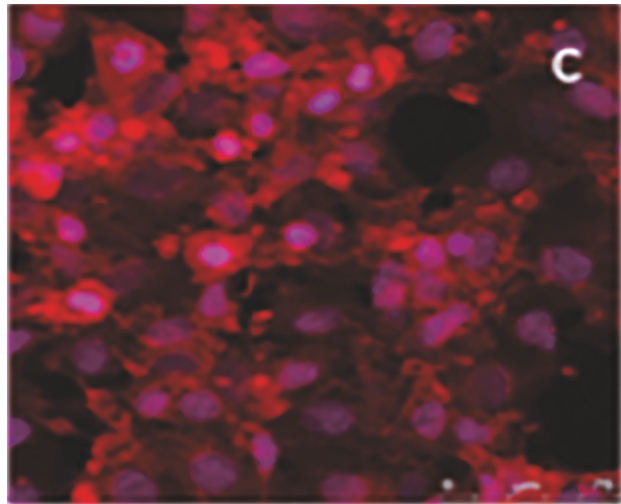

(c)

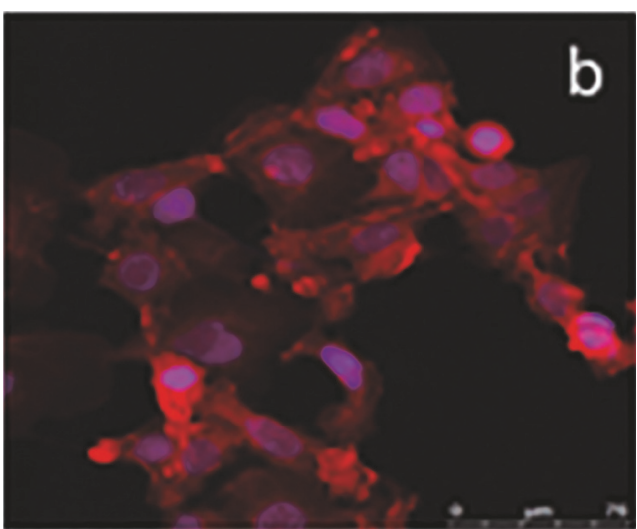

(b)

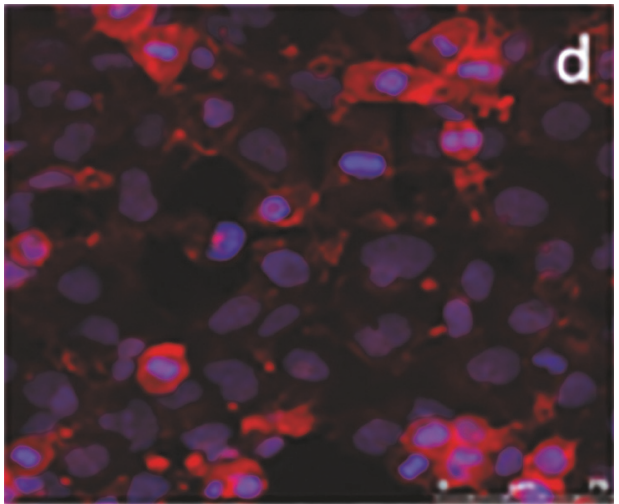

(d)

FIGURE 8: Colorectal adenocarcinoma (Caco-2) cells after 24-hour culture with (a) $150 \mathrm{ng} / \mathrm{ml}$ phorbol 12-myristate 13-acetate (PMA) (b) and $150 \mathrm{pg} / \mathrm{ml}$ hydroxocobalamin (c) or $1000 \mathrm{pg} / \mathrm{ml}$ hydroxocobalamin (d).

diacylglycerol, a natural ligand to PKC. It has been used to promote inflammation both in vitro $[15,16,18]$ and in vivo [19]. $200 \mathrm{mg} / \mathrm{ml}$ PMA showed the greatest increase in NO production (Figure 1) along with the greatest increase in cell activity (Figure 2). However, a distinct increase in both cell activity and NO production was seen from concentrations as low as $100 \mathrm{ng} / \mathrm{ml}$ of PMA. Cell morphology showed clear alterations from the formation of cell clusters with a smooth cobblestone appearance to rougher surface morphology where the individual cell nucleus was larger and the cells were less uniform with the addition of PMA (Figure 3). Similar morphological changes have been observed in other studies, where cells incubated with PMA and IFN- $\gamma$ showed changes when viewed using phase contrast microscopy [16]. Due to the insidious nature of inflammatory disease a midrange activation concentration of $150 \mathrm{ng} / \mathrm{ml}$ of PMA was chosen for the model as this dose generated a significant increase in cell activity alongside moderate increase in NO production which can be associated with low grade inflammation.

For the toxicity study, we used the biologically active form of the vitamin, methylcobalamin, because it can be used as a coenzyme by the cell without conversion. Clinically relevant doses were used in this study to reflect current treatment regimes. The methylcobalamin did not show any significant increase in cell activity (Figure $4(\mathrm{a})$ ) or in NO production
(Figure 4(b)). These data confirm the lack of gastric epithelial cell toxicity of methylcobalamin which was used up to values five times greater than the upper limit of cobalamin $(5000 \mathrm{pg} / \mathrm{ml})$. This high concentration and lack of toxicity are supported by clinical trials in Japan, where patients with peripheral neuropathy were treated with $25 \mathrm{mg} /$ day IV methylcobalamin [20] over 10 days for five months. This is $2.5 \times 10^{10}$ times greater than the recommended dose for patients with PA who are given $1 \mathrm{mg} / \mathrm{ml}$ every $8-12$ weeks. These high doses showed no adverse side effects to patients, which is supported by our in vitro model. Similarly, high concentrations of inactive cobalamin are used clinically to treat cyanide poisoning at very high doses of 4-5 g repeated over consecutive days [11]. Reported side effect were only as a transient urticarial rash; therefore toxicity is minimal with extremely high doses over the short term.

The in vitro model was developed to observe the impact of the atrophic gastritis on the cells of the gastric epithelium, as the action of the cells can be linked to the progression and development of the disease. In this model inflammation was achieved by the addition of $150 \mathrm{ng} / \mathrm{ml}$ PMA. This concentration was identified as it generated an increase in NO production from the cell alongside cell morphology alterations, both of which are proposed to reflect a change in function of the cell associated with low grade inflammation, 
as identified clinically in patients suffering from autoimmune conditions. To observe the effect of the different cobalamins, clinically relevant doses were incubated with the model.

Change in morphology lends itself to a change in function; individual Caco- 2 cells observed under inflamed conditions in this model separated from the continuous monolayer associated with a fully functional gastric lining, therefore losing cell-cell tight junctions as seen in normal culture. The lack of continuous monolayer and loss of tight junctions can themselves act as an inflammatory trigger exacerbating the situation, potentially leading to chronic inflammation associated with comorbid conditions such as gastric cancer. Similarly ultrastructural alterations have also been implicated in altered cell proliferation and cellular kinetics both of which will impact the structure, function, and integrity of the epithelial lining [22].

The cells in this model demonstrated the ability to return to more typical morphology postinflammatory stimuli after incubation with higher levels of cobalamin, giving a more clinically reflective model of acute pathological conditions characterised by excessive NO production in the intestine, which leads to the increased permeability of cells, a potential trigger of inflammatory disease [20].

Methylcobalamin showed no observable differences towards the suppression of NO (Figure 5); however this may have been masked by the increased cell activity observed at higher concentrations in the presence of inflammatory stimuli (Figure 5).

This could be due to the availability of the biologically active form for inclusion into the normal cell processes of DNA methylation and the Krebs cycle as postulated [1]. It may also be that the upregulation of these processes has prevented the availability of the methylcobalamin for the purpose of NO inhibition. This implies a prioritisation of basic cell function over its protective role. Despite the lack of observable NO inhibition, morphological studies highlighted the return of the cell morphology to be more reminiscent of the control cells on the addition of the biologically active cobalamin in the presence of the inflammatory stimuli.

By contrast the inactive hydroxocobalamin showed no observable increase in cell activity (Figure 6(b)), combined with a trend towards a reduction in the amount of freely available NO under inflammatory stimuli. Indeed, there is a significant difference between cells incubated with PMA and hydroxocobalamin at 200 and $500 \mathrm{pg} / \mathrm{ml}$ and their respective counterparts without PMA. The biologically inactive nature of hydroxocobalamin may prevent its immediate uptake into cellular processes as it needs to be converted to methylcobalamin before it can be used by the cells [17], allowing it to remain available for the "mopping" up of endogenous NO. Cellular pretreatment with inactive cobalamin has been noted in previous studies as preventing the process of apoptosis [23].

The reduction in $\mathrm{NO}$ concentration with the addition of cobalamin was highlighted but not significant in these studies; it is hypothesised that this is due to the mimicking of a low grade inflammatory condition. Birch et al. [24] further demonstrated the antioxidant potential of cobalamin conferred by its ability to reduce NO concentrations. Similarly, studies have also shown an increase in the transporter protein transcobalamin in acute and chronic inflammatory states [11].

Methylcobalamin serves to reduce homocysteine to methionine via methionine synthase, which alongside ATP ensures the methylation of RNA, DNA, and proteins linked with endothelial cell dysfunction and the formation of reactive oxygen species (ROS) including NOS [11]. As a result, patients with cobalamin deficiency possess a decreased ability to inhibit NO alongside an increased NO production, promoting a perpetual inflammatory state with systemic clinical impact. Indeed, increased homocysteine levels are associated with the induction of apoptosis in human bone marrow stromal cells, human umbilical vein endothelial cells, and endothelial progenitor cells; the apoptosis was shown to be prevented by the pretreatment with inactive cobalamin metabolism [21].

The concentration range of clinically acceptable plasma cobalamin varies between countries. In the UK, patients are considered borderline abnormal when the cobalamin levels are between 120 and $180 \mathrm{pg} / \mathrm{ml}$ and below $120 \mathrm{pg} / \mathrm{ml}$ is an abnormal result [12]. In Asian countries the lower limit is $500 \mathrm{pg} / \mathrm{ml}$ [21]. This discrepancy means patients who are considered normal in European countries would be considered as having a low cobalamin elsewhere, and so patients with cobalamin deficiency will be missing out on treatment, leading to further deterioration of their condition before diagnosis causing great distress for the patient. In this study, low concentrations of cobalamin $(200 \mathrm{pg} / \mathrm{ml})$ benefitted gastric epithelial cells in an inflammatory environment by restoring some of the features of normal gastric cell morphology; however the cells still remained fairly atypical in shape and size. It can be argued that patients presenting with symptoms and cobalamin levels less than $500 \mathrm{pg} / \mathrm{ml}$ should receive cobalamin treatment as the levels in the body may not be sufficient to reduce excessive inflammation. This would move the UK lower limit of normal in line with that of Asia.

The recommended treatment of cobalamin deficiency is not sufficient for a large number of patients [8]; its symptoms are systemic as a result of the importance of cobalamin in DNA replication and respiration. This study demonstrated that PMA is a suitable inducer of low grade gastric inflammation; it highlights that different forms of cobalamin may be more suitable for treatment due to their ability to be taken up with cellular processes. This work has highlighted that levels below those currently administered promote a beneficial cellular effect; overall more investigation is needed to define to optimal treatment approach based on cellular activity and health, not defined by the systemic tolerance of healthy individuals.

\section{Conflicts of Interest}

The authors declare that there are no conflicts of interest regarding the publication of this paper.

\section{Acknowledgments}

Thanks are due to the Pernicious Anaemia Society for providing cobalamin for use in this project. 


\section{References}

[1] M. Yakut, Y. Üstün, G. Kabaçam, and I. Soykan, "Serum vitamin B12 and folate status in patients with inflammatory bowel diseases," European Journal of Internal Medicine, vol. 21, no. 4, pp. 320-323, 2010.

[2] F. Alderuccio, J. W. Sentry, A. C. J. Marshall, M. Biondo, and B. H. Toh, "Animal models of human disease: experimental autoimmune gastritis - a model for autoimmune gastritis and pernicious anemia," Clinical Immunology, vol. 102, no. 1, pp. 48-58, 2002.

[3] F. A. Karlsson, P. Burman, L. Lööf, and S. Mårdh, "Major parietal cell antigen in autoimmune gastritis with pernicious anemia is the acid-producing $\mathrm{H}+, \mathrm{K}+$-adenosine triphosphatase of the stomach," The Journal of Clinical Investigation, vol. 81, pp. 475$479,1988$.

[4] J. C. Fyfe, M. Madsen, P. Højrup et al., "The functional cobalamin (vitamin B12)-intrinsic factor receptor is a novel complex of cubilin and amnionless," Blood, vol. 103, no. 5, pp. 1573-1579, 2004.

[5] D. L. V. Greenwood and J. W. Sentry, "Murine experimental autoimmune gastritis models refractive to development of intrinsic factor autoantibodies, cobalamin deficiency and pernicious anemia," Clinical Immunology, vol. 122, no. 1, pp. 41-52, 2007.

[6] M. Hooper, P. Hudson, F. Porter, and A. McCaddon, "Patient journeys: diagnosis and treatment of pernicious anaemia," British Journal of Nursing, vol. 23, no. 7, pp. 376-381, 2014.

[7] K. Boddy, P. King, L. Mervyn, A. Macleod, and J. F. Adams, "Retention of cyanocobalamin, hydroxocobalamin, and coenzyme B12 after parenteral administration," Lancet, vol. 292, pp. 710-712, 1968.

[8] F. S. Mathews, M. M. Gordon, Z. Chen et al., "Crystal structure of human intrinsic factor: cobalamin complex at 2.6- $\AA$ resolution," Proceedings of the National Academy of Sciences of the United States of America, vol. 104, no. 44, pp. 17311-17316, 2007.

[9] A. Miller, M. Korem, R. Almog, and Y. Galboiz, "Vitamin B12, demyelination, remyelination and repair in multiple sclerosis," Journal of the Neurological Sciences, vol. 233, no. 1-2, pp. 93-97, 2005.

[10] A. A. M. Ermens, L. T. Vlasveld, and J. Lindemans, "Significance of elevated cobalamin (vitamin B12) levels in blood," Clinical Biochemistry, vol. 36, no. 8, pp. 585-590, 2003.

[11] C. Wheatley, "The return of the Scarlet Pimpernel: cobalamin in inflammation II-cobalamins can both selectively promote all three nitric oxide synthases (NOS), particularly iNOS and eNOS, and, as needed, selectively inhibit iNOS and nNOS," Journal of Nutritional and Environmental Medicine, vol. 16, no. 3-4, pp. 181-211, 2007.

[12] R. Neilson, "B12 and folate: a practical guide," 2013.

[13] U. Förstermann and W. C. Sessa, "Nitric oxide synthases: regulation and function," European Heart Journal, vol. 33, pp. 829837, 2012.

[14] J. B. Weinberg, Y. Chen, N. Jiang, B. E. Beasley, J. C. Salerno, and D. K. Ghosh, "Inhibition of nitric oxide synthase by cobalamins and cobinamides," Free Radical Biology and Medicine, vol. 46, no. 12, pp. 1626-1632, 2009.

[15] X.-M. Chen and D. D. Kitts, "Determining conditions for nitric oxide synthesis in Caco-2 cells using Taguchi and factorial experimental designs," Analytical Biochemistry, vol. 381, pp. 185-192, 2008.
[16] A. L. Vignoli, R. C. Srivastava, A. Stammati, L. Turco, M. Tanori, and F. Zucco, "Nitric oxide production in Caco-2 cells exposed to different inducers, inhibitors and natural toxins," Toxicology in Vitro, vol. 15, no. 4-5, pp. 289-295, 2001.

[17] I. L. Beales and J. Calam, "Stimulation of IL-8 production in human gastric epithelial cells by Helicobacter pylori, IL-1beta and TNF-alpha requires tyrosine kinase activity, but not protein kinase C," Cytokine, vol. 9, pp. 514-520, 1997.

[18] N. Makon-Sébastien, F. Francis, S. Eric et al., "Lycopene modulates THP1 and Caco2 cells inflammatory state through transcriptional and nontranscriptional processes," Mediators of Inflammation, vol. 2014, Article ID 507272, 12 pages, 2014.

[19] A. Dellinger, Z. Zhou, R. Lenk, D. MacFarland, and C. L. Kepley, "Fullerene nanomaterials inhibit phorbol myristate acetateinduced inflammation," Experimental Dermatology, vol. 18, no. 12, pp. 1079-1081, 2009.

[20] K. Shibuya, S. Misawa, S. Nasu et al., "Safety and efficacy of intravenous ultra-high dose methylcobalamin treatment for peripheral neuropathy: a phase I/II open label clinical trial," Internal Medicine, vol. 53, no. 17, pp. 1927-1931, 2014.

[21] M. Goodman, X. Chen, and D. Darwish, "Are, U.S lower normal $\mathrm{B}_{12}$ limits too low?" Journal of the American Geriatrics Society, vol. 44, pp. 1274-1275, 1996.

[22] G. B. Jerzy Glass and C. S. Pitchumoni, "Atrophic gastritis. Structural and ultrastructural alterations, exfoliative cytology and enzyme cytochemistry and histochemistry, proliferation kinetics, immunological derangements and other causes, and clinical associations and sequellae," Human Pathology, vol. 6, no. 2, pp. 219-250, 1975.

[23] E. S. Moreira, N. E. Brasch, and J. Yun, "Vitamin B12 protects against superoxide-induced cell injury in human aortic endothelial cells," Free Radical Biology and Medicine, vol. 51, no. 4, pp. 876-883, 2011.

[24] C. S. Birch, N. E. Brasch, A. McCaddon, and J. H. H. Williams, "A novel role for vitamin B12: Cobalamins are intracellular antioxidants in vitro," Free Radical Biology and Medicine, vol. 47, no. 2, pp. 184-188, 2009. 


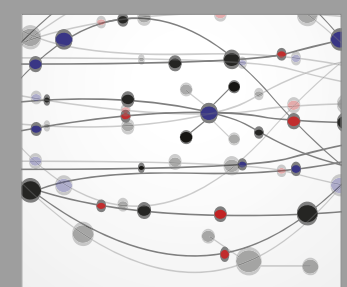

The Scientific World Journal
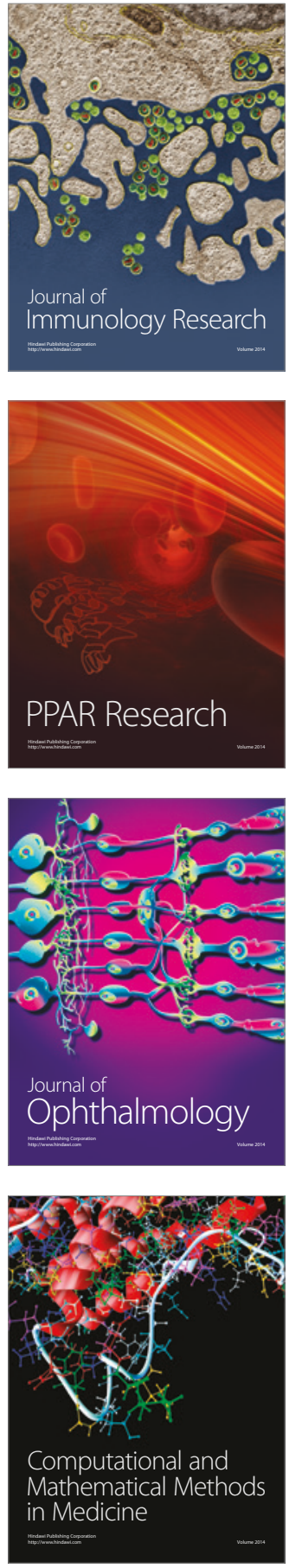

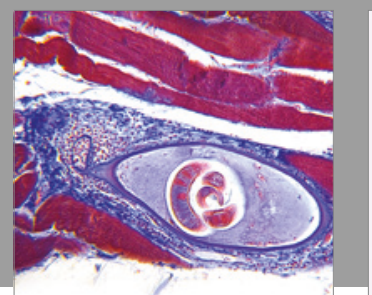

Gastroenterology Research and Practice
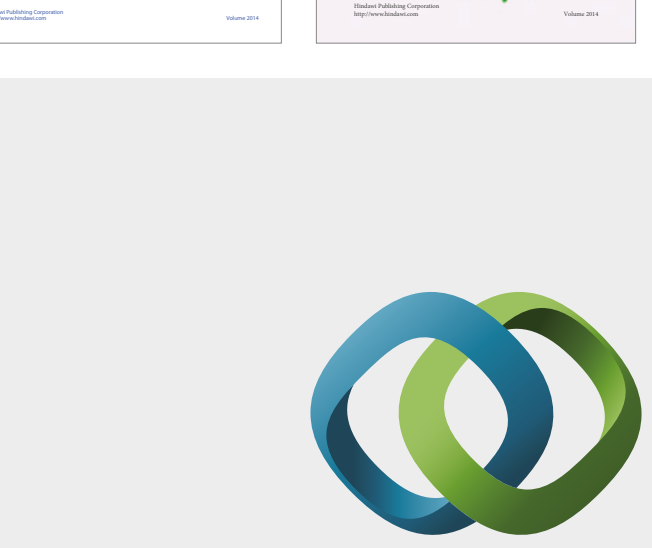

\section{Hindawi}

Submit your manuscripts at

https://www.hindawi.com
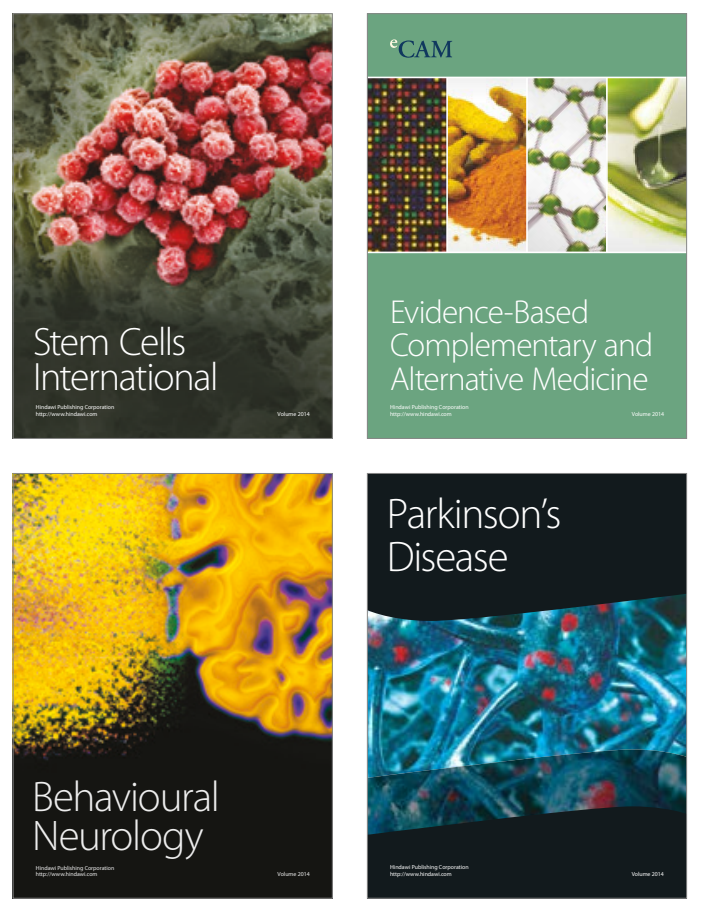
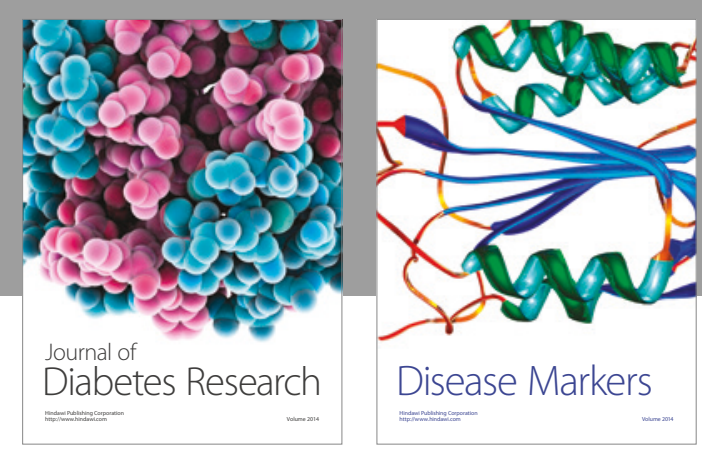

Disease Markers
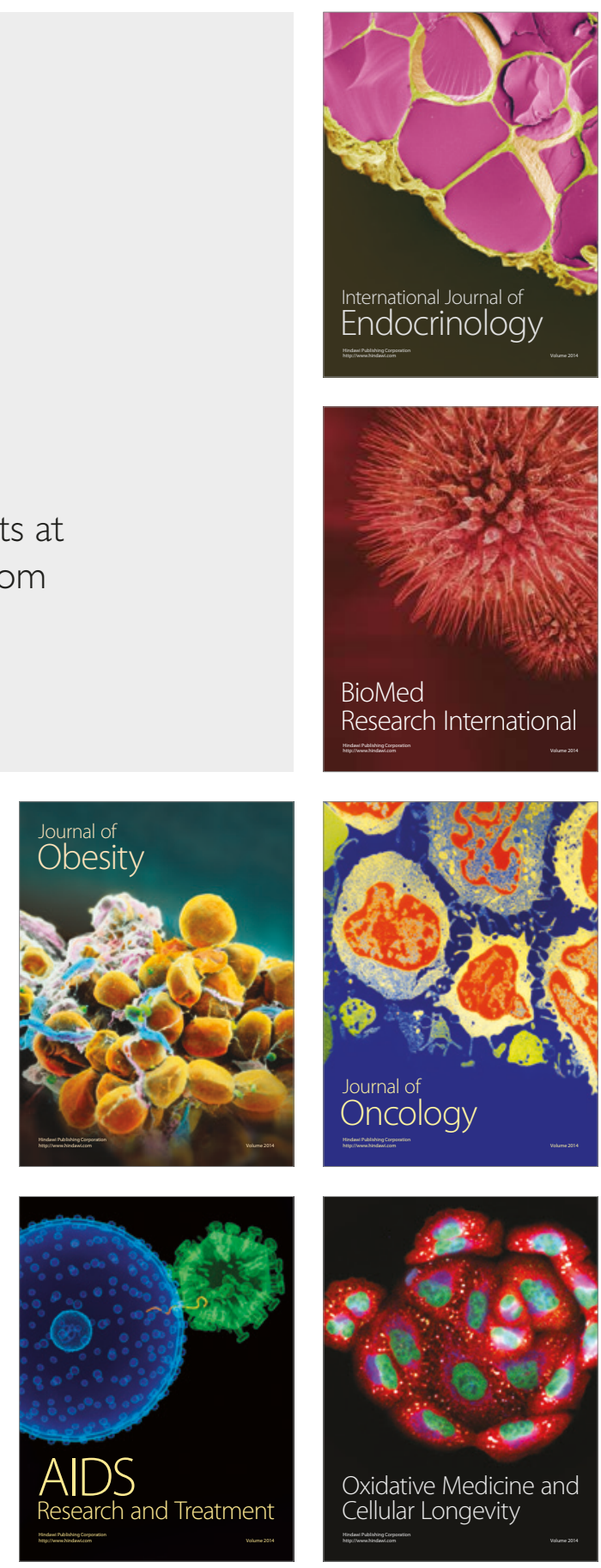